\title{
The Evolution and Summary of Business Environment Research in China
}

\author{
Yonghui CAO; He JIANG*; Jianfeng ZOU
}

\author{
Department of Business Administration, Guangzhou College of Technology and Business, Guangzhou, 510850, China \\ *Corresponding author: He JIANG \\ E-mail: GZhappy2020@126.com
}

\begin{abstract}
with the development of economy and the aggravation of market competition, more and more countries attach importance to the business environment, and our country has taken the construction of business environment as a national strategy. In terms of theory, China has also made active exploration and achieved certain results. Based on the actual situation of research in China, this paper summarizes the theoretical results of the state-owned business environment in order to provide reference for future research and help practice. Keywords: business environment, government behavior, evaluation indexes
\end{abstract}

\section{INTRODUCTION}

In recent years, the business environment report issued by the world bank has attracted the attention of the global theoretical and practical circles. China is in the critical period of economic transformation, and the relevant research on business environment has gradually become the focus of attention of Chinese scholars. Through literature review and combing, domestic research on business environment mainly focuses on the following aspects: research on the relationship between business environment value and government behavior; business environment evaluation; analysis of practical problems in local government business environment governance; business environment optimization strategy research, etc.

\section{The context and evolution of business environment research in China}

\section{1 research on the relationship between business environment value and government behavior}

Some researches on the value and significance of business environment are based on the background of the times and the guidance of national macro policies to explore the value and significance of business environment for economic development (He Lisheng, 2018)[1]. There are also some ways to clarify the important position of business environment in national governance and the path to optimize business environment by analyzing the internal logic agreement between business environment and national governance theory (Lou Chengwu, Zhang Guoyong, 2018)[2]; There are also some studies to study the value and significance of business environment through empirical methods, such as: Dong Zhiqiang, Wei xiahai, Tang canqing (2012) based on the data of the business environment project of the world bank, found that for Chinese cities, a good business environment helps to improve the development of urban economy.[3]

Wei xiahai, Dong Zhiqiang, and Zhang Yongjing (2015) based on the business environment project of the world bank and the investigation and research of Chinese private enterprises in 2008, found that under the better business environment, entrepreneurs can be liberated from non productive activities (such as public relations and Hospitality) and have more time to engage in the daily management of productive activities[4]. Zhang Jiping, Luo Wenping and Liu Yongliang (2017) found that a good business environment is conducive to improving the linkage development of manufacturing industry and logistics industry[5]. Zhou Chao and Liu Xia (2017), based on the evaluation system of business environment of the world bank, analyzed the impact of the host state-owned business environment on the foreign direct investment of Chinese enterprises from the perspective of the investment motivation of Chinese entrepreneurs. The research found that although it has a promoting effect on the whole, the impact of various indicators is different, for example, the impact of access to credit on the relationship between the two is negativ[6]e. Jiang Jing (2017) studied the relationship between the improvement of business environment and the development of service industry in the country based on the data of business environment report of the world bank.[7]

\section{2 research on business environment assessment}

The research on business environment assessment system by Chinese scholars started late, mainly divided into two 
categories: The first is to evaluate the business environment of various provinces and cities in China based on the evaluation index system in the business environment report of the world bank, and put forward corresponding policy suggestions (for example: Hong Hai, 2018)[8]; The other is the business environment evaluation index system with Chinese characteristics based on China's national conditions. Many scholars have pointed out that the evaluation index system of business environment of the world bank is mainly aimed at government supervision and enterprise operation convenience, and is used to evaluate the business environment of 190 economies in the world, so it lacks pertinence and systematization. Therefore, it is necessary to build a business environment evaluation index with Chinese characteristics according to China's national conditions, and put forward targeted policy suggestions beneficial to China's economic development (Peng Xianggang, Ma ran, 2018). Many domestic scholars have constructed a business environment evaluation system for China's economic development practice from different perspectives. For example: Liu Zhirong (2010) pointed out that the evaluation of the business environment of small and medium-sized enterprises in China should be carried out in seven aspects: legal system, society, credit, infrastructure, productive services, market and capital. It also evaluates the business environment of Guangdong, Anhui and Sichuan, and finds that the market and capital environment of small and medium-sized enterprises is an important link to be improved. Wang Ying (2014), based on the evaluation indicators of the world bank and the research on the business environment of Chinese enterprises, listed 15 indicators such as financial access and business license as the most important factors affecting Chinese enterprises. Yang Tao (2015) thinks that due to the unbalanced development of regional economy in China, there are great differences in business environment among provinces. Based on the perspective of small and medium-sized enterprises, the business environment evaluation system is constructed from three dimensions of market environment, policy and government environment, and legal environment. The business environment of four provinces of Shandong, Jiangsu, Zhejiang and Guangdong, which are more developed in economy, is evaluated, and the policy suggestions to improve the business environment of small and medium-sized enterprises are given. Peng Xianggang and Ma ran (2018) pointed out that the evaluation of China's state-owned business environment should pay more attention to the evaluation of public service quality, and be constructed from four dimensions: public service demand identification, public service function, public service capacity and public service supply; Peng diyun, Chen Bo and Liu Zhijia (2019) pointed out that the business environment is the result of the interaction of market, government and society. On this basis, the evaluation index system of regional business environment is constructed, which is evaluated from four dimensions of regional economic environment, market environment, infrastructure and supporting environment respectively. The entropy method is used to evaluate the Yangtze River
Economic Belt in China, and the development law of regional economy in China is found and corresponding policy suggestions are put forward. Although our government has not yet issued a unified business environment evaluation index system, the academic community and governments at all levels have actively explored and accumulated relevant experience according to the economic development of each region, which laid the foundation for the construction of a business environment evaluation system with Chinese characteristics.

\section{3 analysis of practical problems in the management of business environment of local government}

Many scholars have summed up the problems existing in our state-owned business environment. Zhang Wei (2017) thinks that the deficiencies in the current state-owned business environment are mainly reflected in the following aspects: in terms of policies, the stability, continuity and transparency of policies need to be further improved, the legal interpretation and implementation process of policies are inconsistent, and the implementation of policies of different types of enterprises (state-owned enterprises, private enterprises, foreign-funded enterprises, etc.) are inconsistent; In terms of the supply of production factors: the cost of human resources is rising, the supply of land resources is decreasing, the financing cost is high and the convenience is poor, and the tax burden of enterprises is heavy; In the aspect of government service, the relationship between government and market subject is vague, and the level of government service needs to be further improved; In the aspect of legal environment: the level of legal system and the level of intellectual property protection need to be further improved; In terms of trade environment: the convenience of trade management, personnel flow, foreign exchange management and other aspects still need to be further improved; In terms of investment environment: some industries have high threshold for market entry and many hidden barriers. From the perspective of governance, Lou Chengwu and Zhang Guoyong (2018) think that the main problems in the construction of state-owned business environment are: the lack of awareness of the government to optimize the business environment, the lack of the government's cooperative governance concept, the lack of attention to institutional governance, and the lack of understanding of the evaluation indicators of the business environment. As a result, the long-term mechanism to optimize business environment has not been established.

In practice, due to the regional imbalance of China's economic development, as well as the differences in infrastructure construction and culture (especially the administrative culture of the government) among regions, there will be certain differences in the process of local governments' implementation of the central government's laws and regulations on business environment. In addition, 
local governments have certain autonomy in formulating local business environment policies, which results in great differences in business environment among provinces in China. Therefore, in the process of optimizing the business environment, the local government should not only grasp the commonness, but also formulate effective policy documents in combination with the local reality.

\subsection{Strategy Research on business environment optimization}

Through the literature review, we can see that the research on business environment optimization strategies of Chinese scholars can be divided into three categories:

First, from different theoretical perspectives, give the optimization strategies of business environment, for example: Yang Jirui and Zhou Li (2019) based on the perspective of international experience comparison, by comparing the business environment of New Zealand, Singapore and other countries, think that our state-owned business environment optimization should pay attention to the tax burden of small and medium-sized enterprises and the service efficiency and quality of the government; Liu Shuman (2019) pointed out that the key to optimize the business environment is to establish an effective legal system; Ni (2019) analyzed the business environment of Shanghai from the perspective of the business environment of small and medium-sized enterprises. He believed that the core of optimizing the business environment lies in the construction of institutional soft environment, the improvement of the execution effect of the contract, and stressed that more attention should be paid to the improvement of the business environment of small and medium-sized enterprises and private enterprises. That is to say, we should continue to innovate the supervision and service mode based on the market mechanism, and establish a fair and effective industry entry and exit mechanism. Gao Shugui (2019) pointed out that China's state-owned business environment optimization should pay more attention to "one window" platform construction, strengthen industrial integration and other specific measures. Zhou Mingfeng (2018), based on the perspective of harmonious values, points out that the optimization of business environment along the "one belt and one road" should emphasize legalization and the settlement of international trade dispute settlement mechanism.

The second is to study the optimization path of regional business environment in China, for example: Huang Zexuan (2019) analyzed the business environment in Guangxi, and pointed out that to optimize the business environment, the government should also formulate targeted Poverty Alleviation Policies and build a diversified dispute resolution mechanism. $\mathrm{Xu} \mathrm{Ke}$ and Zhou Wei (2019) took Xianxin demonstration area in Shanxi Province as an example, and pointed out that the optimization path of business environment in national demonstration area should pay attention to the administrative management system, policy continuity, legal construction, etc. Wei Shuyan and sun Feng (2017) pointed out that the key to optimize the business environment of the old industrial base in Northeast China lies in the government's pushing forward the reform of the system and mechanism, stimulating the vitality of the technology market, mobilizing all available resources, etc. Third, research on the financing of small and medium-sized enterprises, for example: Jiang Tianhong (2004) pointed out that the key to improve the business environment of small and medium-sized enterprises is to solve their financing problems, and gave suggestions from financing legal system, service system and multi-level capital market; Yu Wenjian and Deng Dini (2008) proposed that financial institutions should set up a special guarantee fund for small and medium-sized enterprises to establish a credit guarantee database for different types of small and medium-sized enterprises, so as to provide guarantee for their financing.

\section{REVIEW OF BUSINESS ENVIRONMENT LITERATURE AT HOME AND ABROAD}

\section{1 differences in research methods of business environment at home and abroad}

Through the review of the above literature, we find that the research methods of business environment in the literature are the combination of theory and practice, the combination of quantitative method and qualitative method. However, there are still some deficiencies in the research on business environment in the existing literature: for example, foreign research focuses on and adopts empirical research methods, through in-depth analysis of data or cases from different countries, so copying foreign research theories is too rough, and the explanation for the problems in the construction of state-owned business environment is insufficient. In comparison, domestic research is based on the practice of environmental construction of state-owned business, which is more in line with China's national conditions. However, from the above literature review, it can be seen that most of the domestic research focuses on the value and impact of business environment construction, that is, the necessity and urgency of optimizing business environment, or the importance of the state-owned business environment to the macro-economic and social development. However, the systematic analysis of government in business environment optimization and the effectiveness of policy-making need to be further studied.

\section{2 there are some differences on the evaluation indexes of business environment}

Since 2003, the world bank has issued the global business environment report for more than ten years. The business 
environment evaluation index system formed by the report has been widely recognized by the theoretical and academic circles. Many empirical studies are based on the evaluation index system. However, this evaluation index system evaluates the business environment of 190 economies in the world, but ignores the differences in politics, economy, culture and other aspects between different economies. Therefore, many scholars question this and propose to build a business environment evaluation index system in line with their own national conditions.

The research on the business environment evaluation index system by domestic scholars is mainly divided into two parts: one part adopts the evaluation index system of the world bank; the other part is aware of the inadequacy of the evaluation index system of the business environment of the world bank, so it is suggested to build a business environment evaluation index system with Chinese characteristics in line with China's national conditions. However, the constructed index system focuses on some aspects of business environment, that is, the domestic academic community has not yet formed a recognized evaluation index system, which leads to less empirical research on business environment in China, and is still based on the evaluation index system of the world bank. In addition, due to the unbalanced development of regional economy in China, there are differences in economy, culture and other aspects in different regions, and local governments have certain autonomy in implementing the laws and regulations related to the business environment of the central government, which makes the business environment in different regions (provinces) have great differences. Therefore, it is difficult to build a business environment evaluation index system with high recognition.

In addition, there are some differences in the evaluation index system of business environment constructed in the existing literature at home and abroad. As a whole, the international index pays more attention to the evaluation of the convenience of business environment, the efficiency of government departments, business cost and the fairness of market, which means that the private sector (private economy) pays more attention to the lawsuit of fair competition and equal status in the market appeal. The domestic indicators pay more attention to the evaluation of the government's behavior, which is mainly because the domestic business environment is established under the guidance of the government, which shows that the evaluation indicators of the business environment of each province are gradually established in the process of optimizing the business environment by the government.

By comparing the business environment rating indicators of different countries in the literature, it is found that the evaluation system adopted in the global business environment report issued by the world bank is not necessarily applicable to every country due to the differences of national conditions. More research is on the basis of the evaluation model, combined with the national conditions, especially the core problems faced, to build a suitable business environment evaluation index and release the business environment report of the country (or region) by professional social organizations for the reference of local governments and relevant departments.

\section{CONCLUSION}

Through the literature review of the existing business environment, it can be seen that the construction of the state-owned business environment in China is government oriented, and the government, as the main body of responsibility for the construction of the business environment, plays an irreplaceable core role in promoting the construction and optimization of the business environment. Based on the perspective of government responsibility, the root of the problems in business environment is the misplacement of government responsibility. Effective government performance is the main way to optimize the business environment. However, in the existing literature, the research on government responsibility in the problems of business environment and optimization path is in a fragmented state, and has not yet formed a perfect system. This is not conducive to the in-depth study and continuous optimization of the problems existing in the construction and optimization of the state-owned business environment.

To sum up, the research on business environment needs to comprehensively and systematically analyze its development status (the experience gained and the existing problems) in combination with the national conditions. The construction of the state-owned business environment is guided by the government, so the internal logic and boundary of the performance of the government's responsibility are the core of the theoretical analysis of the problems in the construction of the business environment according to the national conditions of our country, and also the basic way to put forward the policy suggestions for the continuous optimization of the business environment. Therefore, based on China's basic national conditions, through literature analysis, this study combs the context of state-owned business environment research in order to provide theoretical reference and reference for future research.

\section{ACKNOWLEDGMENT}

This work was financially Sponsored by The 13th five year plan of Education Science in Guangdong Province, 2019 University Philosophy and Social Sciences special research project, the research area of one belt, one road and one big area in Guangdong Bay, Hong Kong and Macao, Serial number 21. 


\section{REFERENCES}

[1] He Lisheng. Improving business environment and building a new open economic system [J]. Research on modern state-owned enterprises, 2018 (9): 16

[2] Lou Chengwu, Zhang Guoyong. Business environment from the perspective of Governance: internal logic and construction ideas [J]. Journal of Liaoning University: Philosophy and Social Sciences Edition, 2018, 46 (2): 59-65

[3] Dong Zhiqiang, Wei Xiahai, Tang Canqing. System soft environment and economic development [J]. Management World, 2012, 4: 9-20

[4] Wei Xiahai, Dong Zhiqiang, Zhang Yongjing. Why is the business environment so important? -Empirical Evidence from "internal and external hustle and bustle" of private entrepreneurs [J]. Economic science, 2015 (2): 105-116

[5] Zhang Jiping, Luo Wenping, Liu Yongliang. Research on the impact of business environment on the linkage development of manufacturing and logistics industry [J]. Journal of management, 2017, 30 (5): 25-33

[6] Zhou Chao, Liu Xia, Gu Zhuan. Business environment and China's Foreign Direct Investment: from the perspective of investment motivation [J]. International trade issues, 2017 (10): 13

[7] Jiang Jing. System, business environment and service industry development -- Evidence from the World Bank's global business environment report [J]. Xuehai, 2017 (January 2017): 176-183

[8] Hong Hai. Optimizing the business environment in an all-round way from the evaluation index system of the world bank [J]. China market supervision research, 2018 (3): $72-74$ 